\title{
The United States Virgin Islands and Hurricanes of 2017
}

\author{
Richard F. Gillum, MD, MS
}

I $\mathrm{n}$ their recent article, Shultz et al. looked at the vulnerability of small island nations highlighted by Hurricanes Harvey, Irma, and Maria. ${ }^{1}$ In the case of New Orleans after Hurricane Katrina, the disaster revealed in a glaring manner the role that racism played in determining the social determinants of health; the poor state of population health prior to the storm; the adequacy or preparedness and response; and hence the vulnerability of residents to death, disease, and displacement from the storm. The US Virgin Islands (USVI), another isolated population of American citizens of African descent, bear great similarities to the devastated Ninth Ward of New Orleans in 2005. In 2017, the media provided daily updates on the unfortunate situation in Puerto Rico but almost never mentioned the USVI. Even a cursory examination of levels and trends in population health indicators in the USVI indicates poor population health there even prior to 2017. The Global Burden of Diseases, Injuries, and Risk Factors 2016 Study (GBD2016) has published estimates of mortality, prevalence, and disability for 265 causes in 195 locations, including the USVI. ${ }^{2-4}$ In 2016, the agestandardized estimated death rates were USVI 813 (731-884) , Haiti 1404 (1214-1614), Puerto Rico 570 (525-616), and the US 578 (569-587). GBD2016 also estimated a summary measure of disease burden, disability-adjusted life years (DALY) as the sum of the estimated years of life lost and years lived disabled. Age-standardized DALY rates were USVI 27,972 (24,329-31,701); Haiti 50,580 (43,520-58,404); Puerto Rico 23,182 (20,300-26,492); and the US $23,975(21,014-27,323)$. In 1990 , the rates in the USVI were death 925 (853-977) and DALY 31,145 $(27,933-34,440)$, somewhat higher than in 2016. The much higher mortality and overall disease burden in the USVI, as compared to Puerto Rico and the US prior to 2017 hurricanes, point to the dire need for disease prevention and health promotion efforts for the over 100,000 residents there, similar to those described by Dzau, Lurie, and Tuckson in New Orleans after Hurricane Katrina and advocated for Texas and Florida. ${ }^{5}$

\section{About the Author}

Howard University College of Medicine, Washington, DC.

Correspondence and reprint requests to Richard F. Gilllum, c/o S. Wolday, Howard University Hospital, Towers Bldg Room 2309, 2041 Georgia Ave NW, Washington, DC 20060, USA

(e-mail: rfg2.howard.edu@gmail.com).

\section{Conflicts of Interest}

The author declares that there are no conflicts of interest.

\section{REFERENCES}

1. Shultz JM, Kossin JP, Shepherd JM, et al. Risks, health consequences, and response challenges for small-island-based populations: observations from the 2017 Atlantic hurricane season. Disaster Med Public Health Prep. 2018:1-13. doi: $10.1017 / \mathrm{dmp} .2018 .28$.

2. GBD 2016 Causes of Death Collaborators. Global, regional, and national age-sex specific mortality for 264 causes of death, 19802016: a systematic analysis for the Global Burden of Disease Study 2016. Lancet. 2017;390:1151-1210.

3. GBD 2016 DALYs and HALE Collaborators. Global, regional, and national disability-adjusted life years (DALYs) for 333 diseases and injuries and healthy life expectancy (HALE) for 195 countries and territories, 1990-2016: a systematic analysis for the Global Burden of Disease Study 2016. Lancet. 2017;390:1260-1344.

4. GBD 2016 Disease and Injury Incidence and Prevalence Collaborators. Global, regional, and national incidence, prevalence, and years lived with disability for 328 diseases and injuries for 195 countries, 1990-2016: a systematic analysis for the Global Burden of Disease Study 2016. Lancet. 2017;390:1211-1259.

5. Dzau VJ, Lurie N, Tuckson RV. After Harvey, Irma, and Maria, an opportunity for better health-rebuilding our communities as we want them. Am J Public Health. 2018;108(1):32-33. 